\title{
THE USE OF A NEW LONG-ACTING TESTOSTERONE ESTER FOR THE ACTIVATION OF SEXUAL BEHAVIOUR IN CASTRATED RABBITS
}

\author{
A. J. ÅGMO \\ Institute of Zoophysiology, Uppsala University, Sweden*
}

(Received 24th October 1973)

Since the early studies by Miescher, Wettstein \& Tshopp (1936), Shapiro (1937) and Hamilton (1937), esterified testosterone in the form of the propionate has been used to activate sexual behaviour in castrated males. Although the propionate has a half-life of 3.75 days in the rat (James, Nicholls \& Roberts, 1969), most investigators have found it useful to inject the hormone daily in order to obtain a maximum effect. This necessitates frequent handling of the animals and subjects them daily to the stress of injection.

In 1960, Diczfalusy reported some properties of a new class of testosterone esters. One of the substances he investigated, testosterone-p-hexoxyphenyl propionate, was found to have a prolonged androgenic effect. Even 90 days after a single injection in castrated rats, the prostate and seminal vesicle weighed about ten times as much as in castrated controls. The onset of the hormonal effect was as rapid as for testosterone propionate. If this ester is capable of activating sexual behaviour in castrated animals, it is possible that a single injection would be sufficient for an experiment of 2 to 3 months' duration.

Nine rabbits of mixed breeds (average wt $3.2 \mathrm{~kg}$ ) were castrated 6 weeks before the beginning of the experiment. Six of the rabbits were injected with $60 \mathrm{mg}$ testosterone-p-hexoxyphenyl propionate (Andradurin ${ }^{\mathbb{R}}$, Leo, Hälsingborg, Sweden). This dose is equivalent to the total amount of testosterone propionate required to restore sexual behaviour in castrated rabbits (Ågmo \& Kihlström, 1974). For comparison, three animals were injected with $15 \mathrm{mg}$ testosterone propionate every 3rd day for 14 days. The animals were subjected to a mating test the day before the first hormone injection, and then once a week for 2 weeks or 5 weeks for the rabbits receiving testosterone propionate or Andradurin, respectively. Five weeks after the last test in this first series, both groups were tested twice at a 1-week interval. The testing procedure has been described elsewhere ( $\AA$ gmo \& Kihlström, 1974). Text-figure 1 shows that both testosterone propionate and Andradurin caused a rapid increase in the number of ejaculations achieved during the mating tests. The increase was faster after the Andradurin injections, but there was no such difference with regard to the increase in the number of mounts (Text-fig. 2). Since most of the animals in the group injected with Andradurin had extensive sexual experience before cas-

\footnotetext{
* Postal address: Box 560, 75122 Uppsala, Sweden.
} 


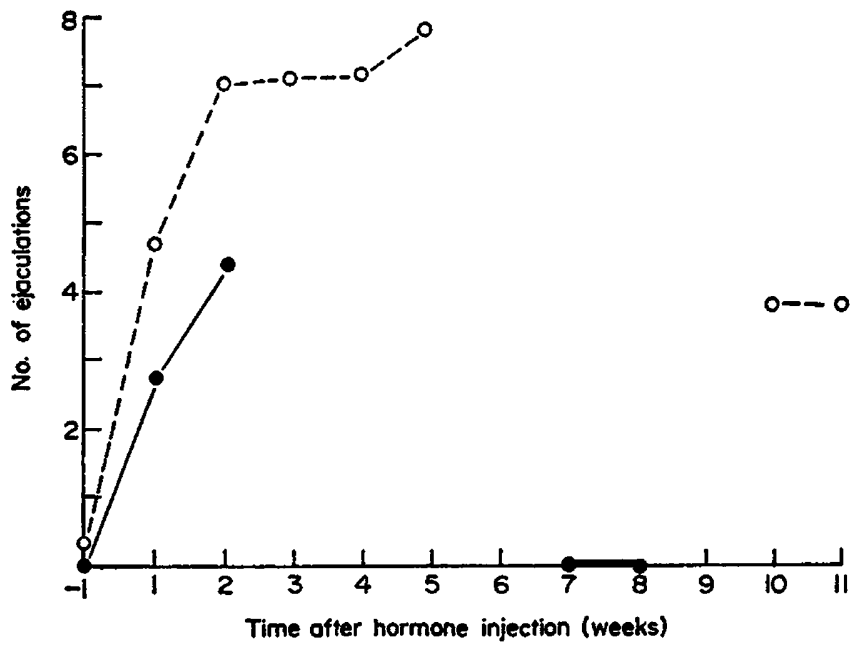

Text-Fig. 1. The relationship between the number of ejaculations achieved during a 30min mating test and the time after injection of testosterone propionate $(\bullet)$ or testosteronep-hexoxyphenyl propionate $(0)$.

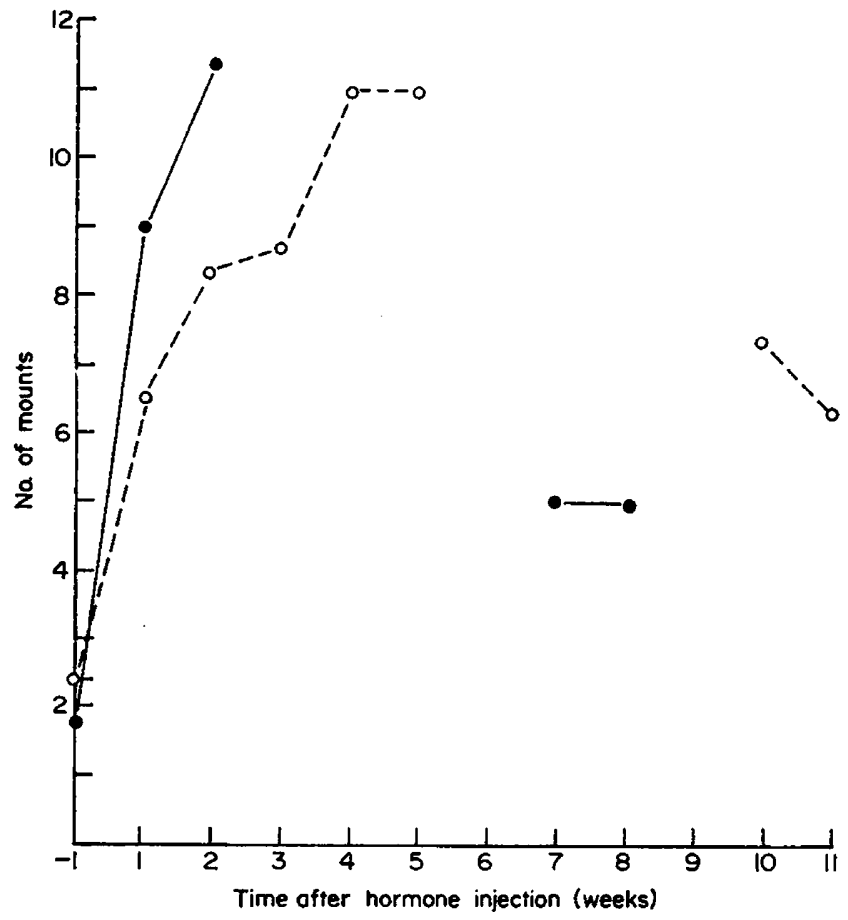

Text-FIG. 2. The relationship between the number of mounts achieved during a 30-min mating test and the time after injection of testosterone propionate $(\bullet)$ or testosterone-phexoxyphenyl propionate $(0)$. 
tration, whereas those injected with testosterone propionate had only limited sexual experience, the observed differences may have been the result of dissimilar background rather than of a difference between the testosterone esters. The other variables studied, i.e. mount and ejaculation latencies and postejaculatory refractory periods, showed the same changes after the two esters had been injected. The level of sexual activity reached 2 to 3 weeks after the injection was higher in animals injected with Andradurin than that usually observed even in intact animals. The animals in this study produced an average of six ejaculations per mating test before castration.

Five weeks after the last hormone injection, the rabbits injected with testosterone propionate had ceased to ejaculate. Ten weeks after the single injection of Andradurin, however, the animals showed a somewhat reduced but still significant number of ejaculations. With regard to the number of mounts, there were no significant differences between the two groups. As has already been shown by Stone (1932), the ability to ejaculate is lost before the ability or desire to mount, presumably as a result of difficulty in maintaining an adequate erection.

The present data show that Andradurin is capable of activating sexual behaviour in castrated rabbits with a single injection. The latency to onset of the hormonal effects is comparable to that of testosterone propionate. In a previous study by Ågmo \& Kihlström (1974), a period of 60 days of testosterone propionate injections was required before the animals showed normal intensity of sexual activity, whereas 2 weeks were enough in this study. The only difference between the two experiments was that the animals in the study by Ågmo \& Kihlström (1974) had been castrated at least 3 months before the beginning of hormone injections. It seems, therefore, that the time between castration and androgen replacement is a critical variable in determining the latency to onset of hormonal effects in rabbits.

The use of the testosterone ester, p-hexoxyphenyl propionate, makes frequent injections over long periods of time unnecessary, and is thus very suitable for long-term behavioural experiments where it is desirable to avoid unnecessary disturbance of the animals.

Financial support from Längmanska Kulturfonden is gratefully acknowledged.

\section{REFERENGES}

$\AA_{G M O}$, A. \& Kinlström, J. E. (1974) Sexual behaviour in castrated rabbits treated with varying doses of testosterone. Anim. Behav. (in press).

Diczralusy, E. (1960) A new class of long-acting steroid hormone esters. Acta endocr., Copenh. 35, 59.

HamiLton, J. B. (1937) Treatment of sexual underdevelopment with synthetic male hormone substance. Endocrinology, 21, 649.

James, K. G., Nicholls, P. J. \& Roberts, M. (1969) Biological half-lives of $\left[4-{ }^{14} \mathrm{C}\right]$ testosterone and some of its esters after injection into the rat. 7. Pharm. Pharmac. 21, 24.

Miescher, K., Wettstein, A. \& Tshopp, E. (1936) The activation of the male sex hormones. Biochem. F. 30, 1977.

Shapiro, H. A. (1937) Effect of testosterone propionate on mating. Nature, Lond. 139, 588.

Stone, G. P. (1932) The retention of copulatory activity in male rabbits following castration. F. genet. Psychol. 40, 296. 